\title{
Mitigation of Dynamic Effects in a Specific Wind Turbine Generation System through Use of STATCOM
}

\author{
M. D. Lucas, A. F. Carneiro and F. K. A. Lima \\ Power Electronics Applications \& Energy Systems Integration Laboratory (LAPIS) \\ Federal University of Ceara (UFC) \\ Campus of Pici - Fortaleza, 60455-760 Ceará (Brazil) \\ Phone/Fax number: +0055 85 3366-9580 / +0055 85 3366-9574, \\ e-mail: marlosdll@gmail.com, alexandrecarneiro@edu.unifor.br, klima@dee.ufc.br
}

\begin{abstract}
This paper presents studies related to application of a STATCOM (Static Synchronous Compensator) with the goal of providing voltage support to a wind-power system based on DFIG (Double Fed Induction Generator) The STATCOM is connected at the point of common connection (PCC) to mitigate energy quality problems. Scenarios were evaluated with input and output loads of various nature. The results of a model built in software PSCAD / EMTDC were presented and discussed
\end{abstract}

\section{Key words}

STATCOM, DFIG, Wind Generation, Energy Quality.

\section{Introduction}

Concern about environmental degradation due to human activity and the growing demand for electricity increased the interest in boosting investments in renewable energy, such as wind, solar, biomass and Small Hydropower (SHP).

By having a greater economic viability, wind generation, has been highlighting increasingly among the other alternatives. The proof is the exponential growth of installed generating global capacity, which in 2012 reached 282.430MW, according to the Global Wind Energy Council [1]. An immediate impact of this growth is the increased penetration of wind generation, i.e., the effective contribution of this source in the energy matrix. In this regard, we highlight mainly European countries such as Denmark (27\%), Portugal (17\%), Germany (11\%), Spain (16\%), among others [2]. Talking about Brazil, although we have $2.1 \mathrm{GW}$ [3] of installed power, their effective participation in the matrix does not exceed $2 \%$.

Despite the penetration of wind portion be a factor desired for any energy matrix, this also brings some problems. For an efficiently energy extraction in an intermittent system, like the wind, it is necessary the use of converters based on power electronics, to provide an operating frequency and voltage constant, with a wind speed variable, which results, without proper care, the increase in Total Harmonic Distortion (THD\%), extremely undesirable in Electric Power Systems (EPS).

The use of converters for converting wind becomes even more necessary and complex, especially when it comes to variable speed wind power systems in which there is a different behavior for each wind speed.

The wind turbines based on doubly-fed induction machine, known as DFIG (Doubly Fed Induction Generator) are responsible, in the world, for $50 \%$ conversion of wind [4]. In addition to supporting the networks during faults, wind turbines equipped with the machine can contribute to the quality of power generated. It is possible to use specific control strategies for this purpose both the grid-side converter (GSC) and the rotorside converter (RSC) as made in [5]. This machine is connected directly to the grid through the stator, and through bi-directional converter AC-DC-AC (RSC + GSC), known as back-to-back, through the rotor. The converter back-to-back processes only a portion of the energy generated by the machine. Although approximately half of the market is dominated by wind turbines with this type of machine, there are a considerable number of older turbines based on induction machine rotor windings without using the grid-side converter. This architecture while also contain power electronics, is composed only by RSC.

Thus, this paper aims to present improvements in the dynamics of oscillations and small faults in the system performed with the contribution of a STATCOM in Point Connection Common (PCC) of a wind turbine based on DFIG in the absence of GSC. So will be analyzed: voltage, frequency, active and reactive power. At the end of the study will be a comparison for systems both with and without STATCOM in wind turbines based on DFIG without GSC. To prove improved dynamic provided by 
STATCOM, simulations were performed in software PSCAD / EMTDC.

\section{Wind turbines equipped with DFIG}

As highlighted previously, with demands for more stringent grid codes, wind turbines connected to the grid should, not only provide energy to support grid stability in the event of failure. This leads to additional complexity to the control system of static converters. Through a DC bus link between the two converters, the control must be performed independently. This means that the RSC should be responsible for the control of active and reactive power of the DFIG stator while the GSC, to ensure. proper operation of RSC, should regulate the voltage at DC link. To have energy flux towards the GSC to the grid is necessary that the slip of the machine is less than 1. For better understanding Fig. 1 shows the schematic of a wind turbine based on this type of machine.

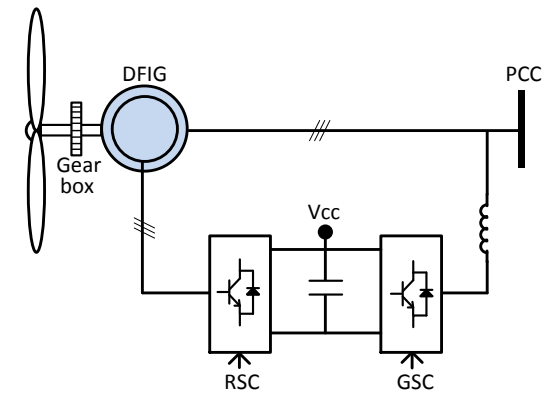

Fig. 1. Configuration of a wind turbine based on DFIG.

\section{A. Mathematical modelling}

The equations of voltages for the stator and rotor are in their respective references shown in (1) and (2) respectively:

$$
\begin{aligned}
& \vec{v}_{s}^{s}=R_{s} \vec{\imath}_{s}^{s}+\frac{d \vec{\psi}_{s}^{s}}{d t} \\
& \vec{v}_{r}^{r}=R_{r} \vec{\imath}_{r}^{r}+\frac{d \vec{\psi}_{r}^{r}}{d t}
\end{aligned}
$$

When on the synchronous referential (1) and (2) can be written as:

$$
\begin{aligned}
& v_{s d}=R_{s} i_{s d}+\frac{d \psi_{s d}}{d t}-\omega_{s} \psi_{s q} \\
& v_{s q}=R_{s} i_{s q}+\frac{d \psi_{s q}}{d t}+\omega_{s} \psi_{s d} \\
& v_{r d}=R_{r} i_{r d}+\frac{d \psi_{r d}}{d t}-\omega_{s l} \psi_{r q} \\
& v_{r q}=R_{r} i_{r q}+\frac{d \psi_{r q}}{d t}+\omega_{s l} \psi_{r d}
\end{aligned}
$$

From the above equations it is possible to show a model of a doubly fed induction generator can be represented by two independent circuits, one for direct-axis components and quadrature axis to another, as shown in Fig. 2.

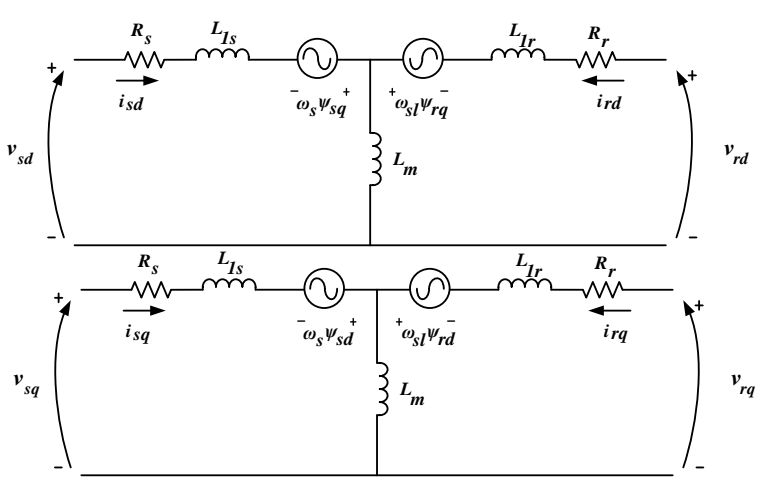

Fig. 2. Circuit modeling of DFIG for axes $d$ and $q$.

\section{B. RSC Control system}

The following equation shows that the electromagnetic torque depends directly on the direct and quadrature components of the magnetic flux.

$$
T_{e}=\frac{3}{2} p\left(\psi_{s q} i_{s d}-\psi_{s d} i_{s q}\right)
$$

Through the control oriented by applied field to the control of RSC is possible to align the coordinate system $\mathrm{dq}$ with the direct component of the flow and thus the cancellation of its quadrature component, resulting in:

$$
T_{e}=-\frac{3}{2} p \psi_{s d} i_{s q}
$$

The stator active power is given by:

$$
p_{s}=v_{s d} i_{s d}+v_{s q} i_{s q}
$$

However as stator voltage is advanced in almost $90^{\circ}$ by the flow of the machine, causes the direct component is zero, in other words:

$$
p_{s}=v_{s q} i_{s q}
$$

Analogously, the control of reactive power of the stator is given by:

$$
q_{s}=v_{s d} i_{s q}-v_{s q} i_{s d}
$$

or

$$
q_{s}=-v_{s q} i_{s d}
$$

Writing the stator currents as a function of the rotor currents, it has been:

$$
i_{s}=\underbrace{\left[\left(\frac{1}{L_{s}} \psi_{s d}-\frac{L_{m}}{L_{s}} i_{r d}\right)\right.}_{\boldsymbol{i}_{\boldsymbol{s} \boldsymbol{d}}}+\underbrace{\left.\left(-\frac{L_{m}}{L_{s}} i_{r q}\right)\right]}_{\boldsymbol{i}_{\boldsymbol{s q}}}
$$

and

$$
q_{s}=-\frac{v_{s q}^{2}}{\omega_{s} L_{s}}+\frac{L_{m}}{L_{s}} v_{s q} i_{r q}
$$


Thus, as shown by (14) and (15), both the active and the reactive power generated by the stator can be controlled with the rotor current. Before analyzing the block diagram of Fig. 2, it is necessary to consider that, for the full operation of the control is necessary decoupling between the direct and quadrature axes, and consider in synchronization angle, slipping the machine.

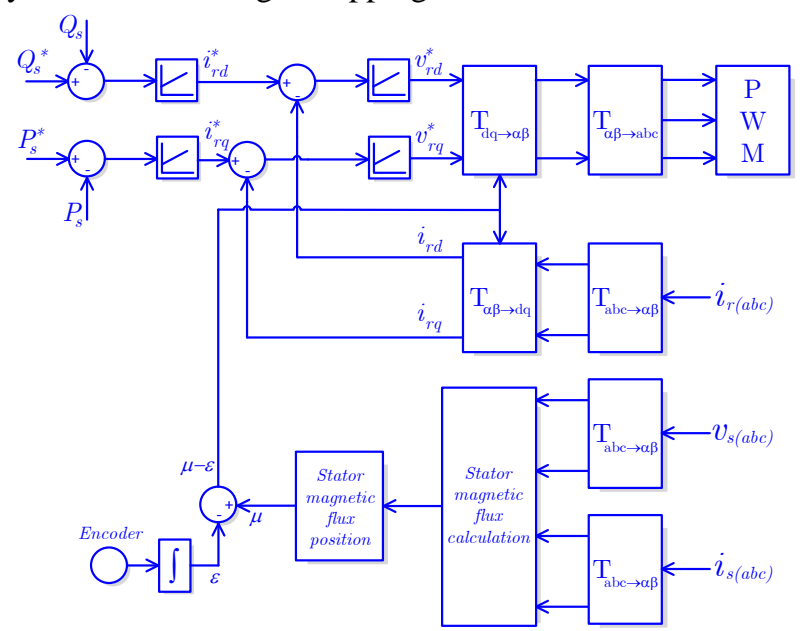

Fig. 3. Block diagram of the control of the RSC.

\section{GSC Control system}

To the control of grid-side converter is commonly used the voltage-oriented control. To accomplish this it is necessary that the grid voltage is represented by a rotating vector, given by:

$$
\vec{v}_{s}=\frac{2}{3}\left(v_{s a}+v_{s b} e^{j \frac{2 \pi}{3}}+v_{s c} e^{j \frac{4 \pi}{3}}\right)
$$

With synchronization, the direct axis component of the voltage $\overrightarrow{\mathbf{v}}_{\mathbf{s d}}$ has the same module of the grid-voltage $\mathbf{V}_{\mathbf{s}}$ while $\overrightarrow{\mathbf{v}}_{\mathbf{s q}}=\mathbf{0}$. Thus, after analysis of the circuit converter, it is obtained following expressions in the synchronous referential:

$$
\begin{aligned}
& v_{s d}=R i_{d}+L \frac{d i_{d}}{d t}-\omega_{e} L i_{q}+v_{d} \\
& v_{s q}=R i_{q}+L \frac{d i_{q}}{d t}-\omega_{e} L i_{d}+v_{q}^{*}
\end{aligned}
$$

Ignoring losses the active power can be expressed as:

$$
P_{c c}=V_{c c} I_{G S C}=\frac{3}{2} v_{s d} i_{d}=P_{c a}
$$

Through current capacitor, has:

$$
C \frac{d V_{c C}}{d t}=I_{G S C}-I_{R S C}
$$

But, $\mathbf{I}_{\mathbf{G S C}}$ is defined as:

$$
I_{G S C}=\frac{3 m_{1}}{4 \sqrt{2}} i_{d}
$$

As $\mathbf{m}_{\mathbf{1}}$, the modulation index, can reewrite (20), as:

$$
C \frac{d V_{c c}}{d t}=\frac{3 m_{1}}{4 \sqrt{2}} i_{d}-I_{R S C}
$$

The reactive power of the GSC is given by:

$$
Q_{r}=\frac{3}{2}\left(v_{s d} i_{q}-v_{s q} i_{d}\right)=\frac{3}{2} v_{s d} i_{q}^{*}
$$

Therefore, by (19), (22) and (23) is possible to note that the control of active power converter and DC-link voltage, is performed by direct component of the gridcurrent $\mathbf{i}_{\mathbf{d}}$ while the reactive power of the GSC, is controlled by the quadrature-axis component. The block diagram of this control is shown in Fig. 4 [4].

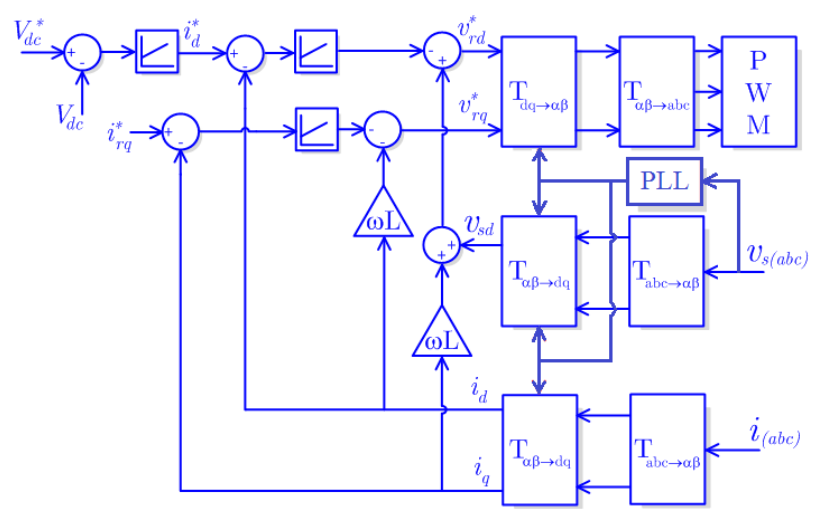

Fig. 4. Block diagram of the control of the CLR.

\section{STATCOM}

The first FACTS devices have appeared with the aim of compensate dynamically transmission lines and, thereby, increase system stability. Others FACTS devices can operate in voltage regulation at a given point of the power grid. In this class of devices its possible to find the STATCOM. In this topic, will be shown the structure of this device, as well as its control system.

\section{A. Structure of the STATCOM}

The schematic model of the STATCOM involved in its structure, a power inverter, a capacitor DC and a transformer coupling according to Fig. 5.

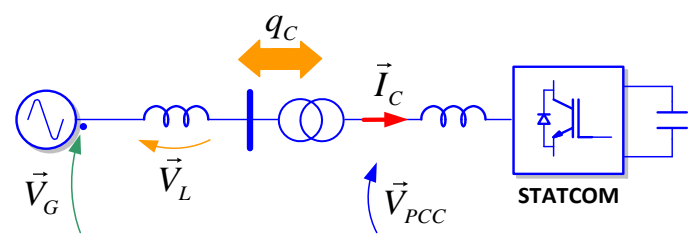

Fig. 5. Structure of the STATCOM.

In turn, the six-pulse inverter using semiconductor switches, usually IGBTs, for switching and, through the energy stored in the capacitor DC, is capable of generating a synchronous three-phase voltage on its output terminal [7]. Representative inverter topology is shown in Fig. 6. 


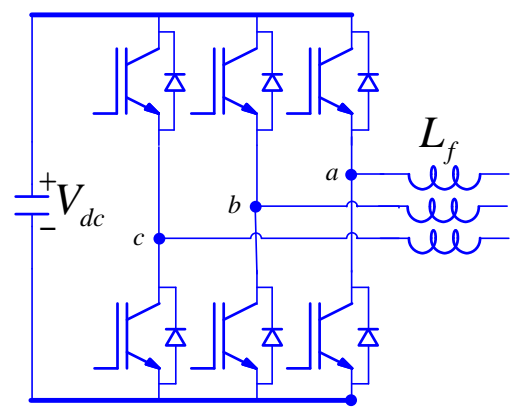

Fig. 6. Six-pulse inverter.

The STATCOM injects compensating current of variable magnitude at the PCC [6]. This is possible since the STATCOM working as a voltage source controlled by injecting reactive current in the system in a controlled manner.

One of the main benefits of STATCOM for a transmission line is the voltage regulation along the transmission line through reactive power compensation.

According to the literatures [7]-[8], the compensation of reactive is used to regulate the voltage, both the mid-point (or intermediate) as the end of the line, preventing the instability of the voltage, as well as the dynamic control voltage in order to increase stability and improve the transient damping of power oscillations.

\section{B. Control System of STATCOM}

The control system for the STATCOM model used in this work was based on active power theory and instantaneous reactive [9], one of several control to STATCOM. The model used modulation hysteresis band [10].

Since the voltages and currents, in the more general case, can contain imbalances and harmonics, the real power and imaginary powers instantaneous will be formed by average components and oscillating, as shown in (24) and (25).

$$
\begin{aligned}
& p=\bar{p}+\tilde{p} \\
& q=\bar{q}+\tilde{q}
\end{aligned}
$$

Where the " " represents the power average value and the “ " represents the oscillating part.

The physical meaning of the real power and imaginary can be summarized by Fig. 7, where the real power output of the zero sequence $\mathrm{p}_{0}$ represent the total energy flowing through the system, while the imaginary power $q$ represents the energy exchanged between the phases, without any energy transport [7] - [8].

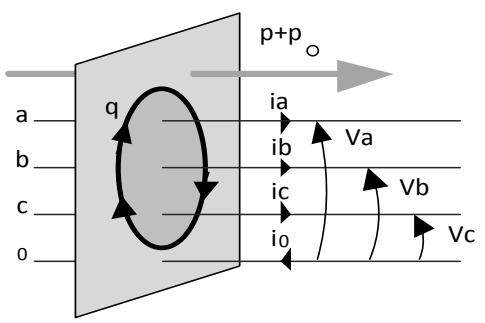

Fig. 7. Instantaneous power flow.
The block diagram of the control strategy shown in Fig. 10 has as variable output, the current of the converter injected into the electrical system in $\alpha \beta$ coordinates system.

According to the control system shown reference signals of the real powers $(\overline{\mathrm{p}})$ and imaginary $(\overline{\mathrm{q}})$ are generated according to the conditions of compensation. These power references with the positive sequence voltage $\left(v_{\alpha \beta}^{+}\right)$produce the reference compensation currents $\left(i_{\alpha \beta}^{*}\right)$. These currents are necessary to maintain the regulation of bus voltage $\mathrm{AC}$ or compensation from FP. The tension in the DC link is controlled by controlling the real power.

Ideally the grid voltage should be composed mainly by positive sequence component. However, eventually, it may contain undesirable components, such as elements of negative sequence and zero, as well as harmonics due to the presence of non-linear loads in the electricity system. Therefore, the control system must, in addition to detecting, make the positive sequence signal as a reference. Since it is quite common to have non-linear loads connected to the electrical system, the structure shown in Fig. 8 is quite usual.

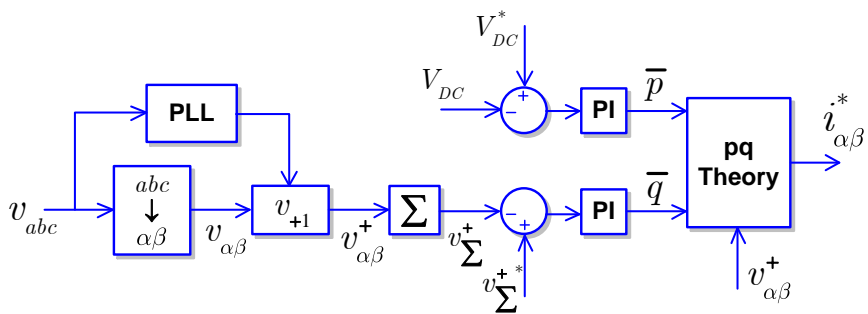

Fig. 8. Blocks diagram of the STATCOM.

The control of the FP when enable, automatically disables the control voltage at the PCC. This happens because the control variable $(\bar{q})$ is the same in both modes.

To compensate for the power factor, it is necessary to calculate the reactive power of the load. One of the methods mentioned in [9] e [10] is called classic mode, which uses the equation for calculating the imaginary power, given by:

$$
q=v_{\beta} i_{\alpha_{\text {carga }}}-v_{\alpha} i_{\beta_{\text {carga }}}
$$

However, for obtaining the average value of the imaginary power $\bar{q}$, it is the use of a low-pass filter, as shown in Fig. 9.

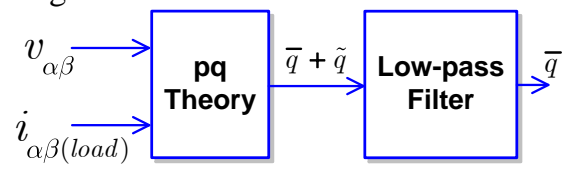

Fig. 9. Calculation of reactive power in load.

The next session will discuss the results of simulations for a scenario that includes a wind turbine based on DFIG and static compensator STATCOM. 


\section{Simulation results}

In this work the simulated system is subject to different dynamics at different instants. The time of activation of the non-linear load as well as the STATCOM on voltage control mode, are $t_{\mathrm{L}}=1.5 \mathrm{~s}$, and $\mathrm{t}_{\mathrm{STC}}=0.7 \mathrm{~s}$, respectively. The simulation has a duration of six seconds. The STATCOM shut down is accomplished in $\mathrm{t}_{\mathrm{STC}_{\text {out }}}=$ $4 \mathrm{~s}$. The scenario simulated system, shown in Fig. 10, have their parameters specified in Tab. 1 .

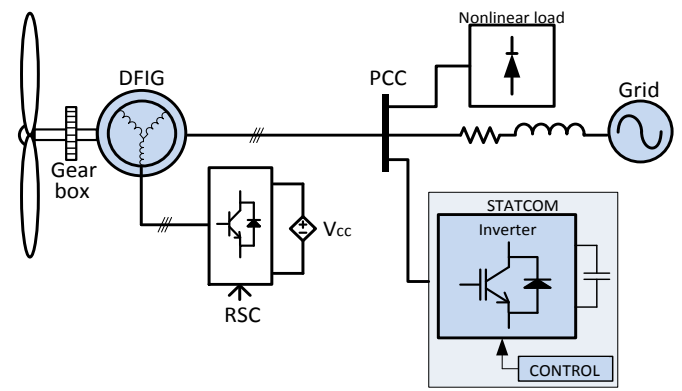

Fig. 10. System composed a turbine with DFIG based on the contribution of a STATCOM.

Tab. 1. Characteristics of the simulated system.

\begin{tabular}{|l|l|}
\hline DFIG Parameters & Values \\
\hline \hline Rated Power & $1,5 \mathrm{MVA}$ \\
Rated Voltage (L-L) & $0.690 \mathrm{kV}$ \\
Base Frequency & $60 \mathrm{~Hz}$ \\
Stator/Rotor Ratio & 1 \\
Mechanical Dumping & $0.001 \mathrm{pu}$ \\
Moment of Inertia & 0,5 \\
Stator Resistence & $0,0054 \mathrm{pu}$ \\
Wound rotor resistence & $0,00607 \mathrm{pu}$ \\
Stator leakage Inductance & $0,108 \mathrm{pu}$ \\
Wound rotor leakage Inductance & $0,110 \mathrm{pu}$ \\
Magnetizing inductance & $4.362 \mathrm{pu}$ \\
Stator/Rotor Turns Ratio & 1 \\
Torque Variable & $0.6 \sim 1.0$ \\
\hline Grid Parameters & Values \\
\hline \hline Voltage & $0.690 \mathrm{kV}$ \\
Resistence & $0,0250 \Omega$ \\
Inductance & $0,00014 \mathrm{H}$ \\
\hline STATCOM Parameters & Values \\
\hline \hline Rated Voltage & $0,690 \mathrm{kV}$ \\
Rated Power & $1 \mathrm{MVA}$ \\
Capacitance & $9400 \mu \mathrm{F}$ \\
DC-Link Voltage & $3,0 \mathrm{kV}$ \\
\hline Load Parameters & Values \\
\hline \hline Rated Voltage & $0,690 \mathrm{kV}$ \\
Rated Power & $1 \mathrm{MVA}$ \\
Indutance & $0.001 \mathrm{H}$ \\
Resistence & $0,09 \Omega$ \\
\hline
\end{tabular}

The Fig. 11 shows the behavior of voltage in PCC under dynamic stress caused by the load and the entry and exit of operation of the STATCOM.

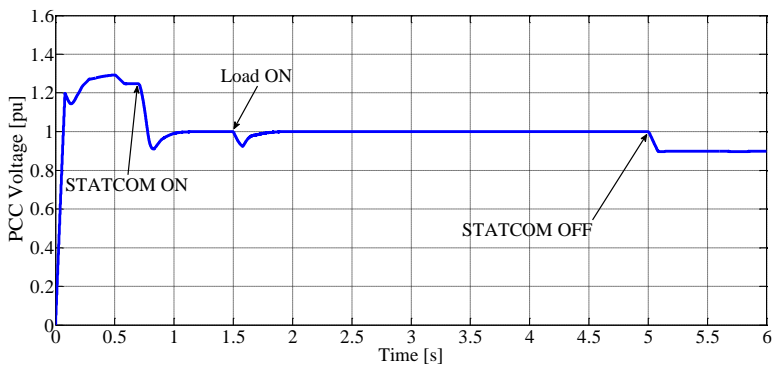

Fig. 11. Graphic of Voltage at PCC.

Is possible to observe that the STATCOM brings a great advantage that is able to regulate the voltage through reactive compensation, in this case, surpluses (loads). In normal operation the offset should reactive DFIG system in accordance with the control shown in Fig. 3, to maintain the system voltage at $1 \mathrm{pu}$.

Fig. 12 shows the oscilation of the system frequency.

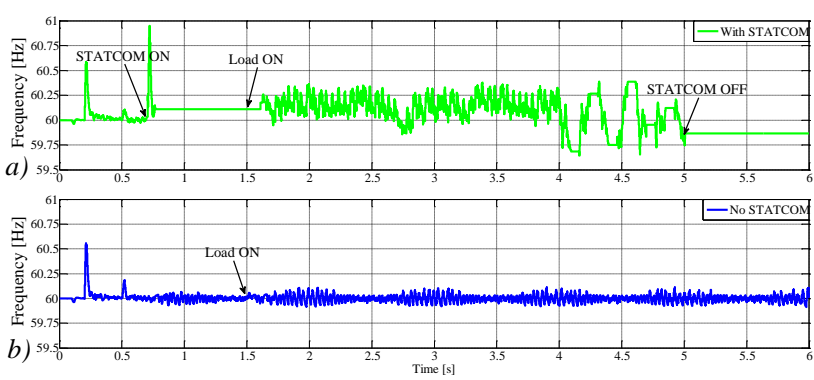

Fig. 12. Behavior of the system frequency with (a) and no (b) STATCOM.

In $a$, can be noted due the increase of $\tilde{q}$, due the STATCOM switching, has caused a intermittent increase on system frequency.

In $b$ is possible perceive that no STATCOM, the intermittence is just due torque variation. Is important knows that variation must be similar to the active power behavior on DFIG due influence of active power on the system frequency.

In order to verify what was said, the Fig. 13 shows the active power variation injected by DFIG and your similar with the grid frequency without the STATCOM influence.

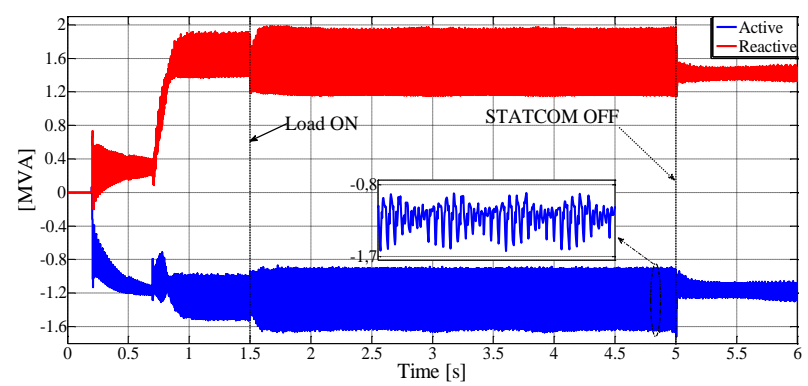

Fig. 13. DFIG Active and Reactive Power Flow.

Worth remembering that variation is due just of load, given that the STATCOM will compensate only the reactive parcel of the power. 
The behavior of the reactive power at PPC, showed on Fig. 14 , brings the expected, i.e., the reactive management of the DFIG and STATCOM to provide a voltage on $1 \mathrm{pu}$.

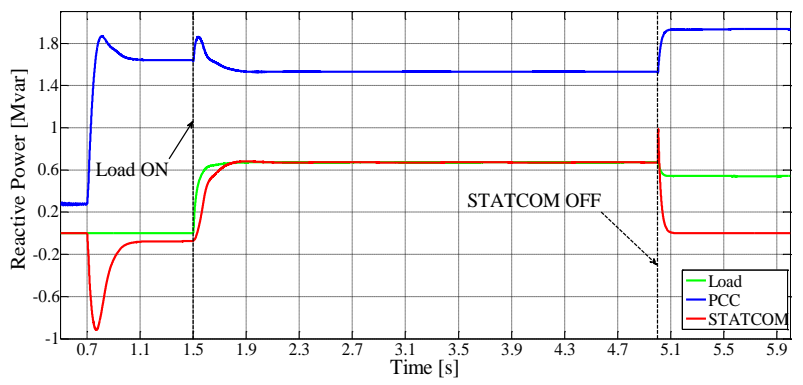

Fig. 14. PCC Load Reactive Power Flow.

Thus, shall be give increased attention at the instant which the load with inductive power $0.66 \mathrm{Mvar}$ is thrown. The STATCOM control makes it compensates the reactive power surplus. This happens due inductive reactive power required to maintain the voltage at the reference has already been satisfied by DFIG.

To show the active power of system, the Fig. 15 brings that due the increase of the DFIG reactive power, the active power must decrease to obey the rated limits.

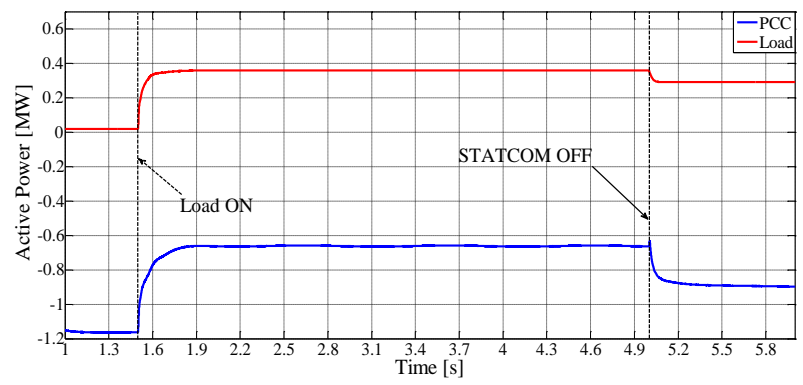

Fig. 15. PCC and Load Active Power Flow.

The difference of values shows that the DFIG active power is injected in the grid.

\section{Conclusion}

This paper presented studies of a static synchronous compensator (STATCOM) operating in conjunction with wind turbines with systems based on DFIG without the grid side converter. Mathematical modeling of the turbine was presented, as well as an approach about the control system so the turbine as the STATCOM.

The control of the turbine operated to let the bus voltage at $1 \mathrm{pu}$, ie when managing the reactive power needed to regulate the voltage at the PCC. It was observed that the FACTS device, in this case, only acted to compensate the reactive power surplus in order not to compromise the rated values of the machine.

The results prove the effectiveness of the device and show that with the STATCOM, the quality of electricity supply is even more guaranteed. The experimental assembly for the validation of this system will be the subject of future work of this research.

\section{Acknowledgement}

The authors would like to thank the Coordination of Superior Level Staff Improvement (CAPES) for the financial support for this research and the National Counsel of Technological and Scientific DevelopmentCNPq (486948/2012-9).

\section{References}

[1] Global Wind Statistics - 2012 - 11.02.2013 http://www.gwec.net/wp-content/uploads/2013/02/GWECPRstats-2012_english.pdf,

Access at: November 04, 2013, 11:37.

[2] Wind in power - 2012 European statistics - February 2013 http://www.ewea.org/fileadmin/files/library/publications/st atistics/Wind in power annual statistics 2012.pdf, Acess at: November 04, 2013, 11:39.

[3] Capacidade de Geração do Brasil, http://www.aneel.gov.br/aplicacoes/capacidadebrasil/capac idadebrasil

Access at: November 04, 2013, 10:56.

[4] Lima, F.K.A. ; Luna, A. ; Rodriguez, P. ; Watanabe, E.H. ; Blaabjerg, F., "Rotor Voltage Dynamics in the Doubly Fed Induction Generator During Grid Faults" Power Electronics, IEEE Transactions on Volume: 25, Issue:1. 2010, pp: 118-130.

Luna, A. ; Lima, F.K.A. ; Santos, D. ; Rodriguez, P. ; Watanabe, E.H. ; Arnaltes, S. , " Simplified Modeling of a DFIG for Transient Studies in Wind Power Applications" Industrial Electronics, IEEE Transactions on Volume: 58, Issue: 1. 2011, pp: 9-20.

[5] L. Ximenes and F. K. A. Lima, "Compensação de Harmônicos e Reativos Utilizando Aerogeradores Equipados com DFIG", Anais do II Simpório Brasileiro de Sistemas Elétricos-SBSA, Belém-PA, 2010.

[6] C. H. R. R. Santos, "Influência do STATCOM na estabilidade de Sistemas Elétricos de Potência," dissertação mestrado, Dept. Eng. Elétrica, UNIFEI, Itajubá, 2003.

[7] A. J. Ortiz; M. Aredes; E. Bueno; P. Rodríguez, "Comparative study of the current and voltage controllers applied to the STATCOM", Indutrial Eletronics Society (IECON) - 33rd Annual Conference of the IEEE, Taipei, Taiwan, Nov. 5-7, 2012.

[8] A. J. Ortiz; M. Aredes; E. Bueno; P. Rodríguez; L. G. B. Rolim, "A New Current Control For The STATCOM Based On Secondary Order Generalized Integrators", IEEE, 2008

[9] E. H. Watanabe and M. Aredes, "Teoria de Potência Ativa e Reativa Instantânea e Aplicações - Filtros Ativos e FACTS," Anais do XII Congresso Brasileiro de Automática-CBA, Uberlândia, v. 1, p. 81-122, 1998.

[10] H. Akagi, E. H. Watanabe, and M. Aredes, Instantaneous Power Theory and Aplications to Power Conditioning. New Jersey: IEEE Press Wiley-Interscience, 2007. 